\title{
Interference of M-protein on prothrombin time test - case report
}

\author{
Sandra Margetić, Ivana Ćelap*1, Lora Dukić1, Ines Vukasović1, Lucija Virović-Jukić2 \\ ${ }^{1}$ Clinical Institute of Chemistry, Medical School University Hospital Sestre milosrdnice, Zagreb, Croatia \\ 2University Department of Internal Medicine, Medical School University Hospital Sestre milosrdnice, Zagreb, Croatia \\ *Corresponding author: ivana.celap@gmail.com
}

\begin{abstract}
The aim of this report was to present a case of interference on prothrombin time (PT) test that directed further laboratory diagnostics and resulted with final detection of monoclonal gammopathy in an 88-year old man. Routine coagulation testing during medical examination at Emergency Department revealed unmeasurable PT ( $<7 \%$ activity) and activated partial thromboplastin time (aPTT) within reference range. After repeated sampling for coagulation testing, PT was unmeasurable again, as well as fibrinogen level $(<0.8 \mathrm{~g} / \mathrm{L})$, thrombin time (TT) was significantly prolonged (107 seconds) and aPTT was within reference range. In both plasma samples refrigerated at $4^{\circ} \mathrm{C}$ overnight, white gelatinous precipitate was visible between the cell and plasma layers and the presence of monoclonal protein (M-protein) was suggested in our patient. Further laboratory diagnostics revealed total serum proteins at concentration of $123 \mathrm{~g} / \mathrm{L}$ and the presence of $\mathrm{M}$-protein $\lg \mathrm{G}$ lambda $(\lambda)$ at concentration of $47.1 \mathrm{~g} / \mathrm{L}$. These results suggested monoclonal gammopathy as an underlying pathophysiological condition in our patient. Activities of coagulation factors II, V, VII and $X$ were within reference ranges or increased. These results and correction of unmeasurable PT result to $67 \%$ in mixing test with commercial normal plasma suggest in vitro rather than in vivo interference of M-protein on PT result. In contrast, significantly prolonged TT results in all analysed samples suggest impact of $M$-protein on this global coagulation test due to possible effect on fibrin polymerization.
\end{abstract}

Keywords: prothrombin time; interference; M-protein; monoclonal gammopathy; thrombin time

\section{Introduction}

Prothrombin time (PT) is the most frequently performed global coagulation test. It is used for assessment of clotting disorders and monitoring of patients taking oral anticoagulant therapy (OAT) with vitamin $\mathrm{K}$ antagonists (VKAs) (1). In patients taking VKAs, unmeasurable PT test result is frequently found due to over-anticoagulation caused by excessive drug dosing (2). Unreliable, incorrect and even unmeasurable PT result in a patient taking VKAs as well as in a patient not taking any anticoagulant therapy, may be caused by inadequate or improper sample for coagulation testing or by endogenous or exogenous interferences. In general, endogenous interferences are usually caused by haemolysis, lipemia and hyperbilirubinemia. Rarely, monoclonal protein (M-protein) can be the cause of endogenous interference on coagulation and other laboratory test results due to high sample viscosity, precipitation and reaction with reagent components (3). In contrast, drugs are common cause of exogenous interferences (4). Test results altered by undetected interferences represent potential danger (5). They are misleading to the clinician and the patient is exposed to risk of unfavourable outcome, especially in emergency care setting.

Although it is known that $M$-proteins can cause abnormal laboratory results, the impact of M-protein on coagulation test results is different in individual patients (6).

The aim of this study was to present a case of interference of M-protein on PT and other coagulation test results. 


\section{Materials and methods}

Venous blood samples for laboratory testing were collected in Vacuette tubes (Greiner Bio-One, Kremsmünster, Austria) containing 3.2\%-trisodium citrate (coagulation testing, volume $1.8 \mathrm{~mL}$ ), $\mathrm{K}_{3} \mathrm{ED}$ TA (haematology, volume $2 \mathrm{~mL}$ ), a clot activator and Li-heparin (biochemistry, volumes 7 and $5 \mathrm{~mL}$, respectively). Patient samples were collected by venepuncture at the Emergency Department (ED) and immediately delivered to the laboratory for analysis. All samples (except for $C B C$ ) were centrifuged at room temperature for 10 minutes at $1800 \times \mathrm{g}$.

Coagulation tests were performed on Behring Coagulation System XP (BCSXP) analyser (Siemens, Marburg, Germany) using original manufacturers' reagents. PT and activated partial thromboplastin time (aPTT) tests were determined by coagulometric method using recombinant human thromboplastin reagent Dade Innovin and Actin FS reagent, respectively. TT was measured by coagulometric method with $\mathrm{BC}$ Thrombin reagent and fibrinogen activity was determined by Clauss clotting method with Multifibren $U$ reagent. The coagulation factors II, V, VII and X were determined by one-stage coagulometric methods using PT reagent (Dade Innovin) and appropriate factor deficient plasmas. PT mixing test was performed by mixing one part of patient plasma with one part of commercial normal plasma (1+1). Coagulation tests were performed within 4 hours from blood sampling, except in sample designated as $3^{*}$.

Complete blood count (CBC) was performed on DxH 800 automated haematology analyser (Beckman Coulter, Brea, CA, USA).

Total protein and $\beta 2$-microglobulin concentrations were quantified on Architect c8000 (Abbott, Wiesbaden, Germany) using total protein reagent ( $A b$ bott Laboratories, Abbott Park, IL, USA) and Quantia ß2-Microglobulin (Biokit, S.A., Barcelona, Spain).

Serum protein electrophoresis was performed using Capillarys (Sebia, Evry Cedex, France) while immunofixation was done on Hydrasys (Sebia, Evry Cedex, France).

The patient signed the written informed consent for the publication of this report according to the ethical guidelines following the Declaration of Helsinki. The institutional ethic committee has also approved our study protocol.

\section{Case report}

An 88-year-old male presented to ED of the Medical School University Hospital Sestre milosrdnice, Zagreb where he underwent medical examination due to general weakness and fresh blood appearance during nose-blowing over the past 10 days. The patient denied spontaneous nose bleeding (epistaxis). He was suffering from hypertension for years and regularly took antihypertensive medication (ramipril/hydrochlorotiazide). During medical examination the patient was conscious, lucid, mobile and afebrile. Standard emergency laboratory tests panel was required. Performing of the biochemical analysis was not possible due to the high viscosity of the serum sample and repeated centrifugation was done. Since the repeated centrifugation did not gain adequate serum sample, plasma sample venepuncture was asked for. Plasma sample did not show the appropriate viscosity for the biochemical test analysis. If the serum/plasma sample viscosity is too high, analyser would report "aspiration error" and processing of sample must be cancelled. Coagulation test results showed unmeasurable result for PT $(<7 \%)$ and aPTT within reference range ( $24 \mathrm{~s}$; ratio 0.8 ) as presented in Table 1 (sample 1). The patient denied use of any anticoagulant medication and a new sample for coagulation testing was requested. Beside PT and aPTT, which showed similar results as in the previous sample, fibrinogen and TT were additionally measured. Fibrinogen level was unmeasurable while TT was significantly prolonged (Table 1 , sample 2 ). The patient was under observation for the next seven hours from his admittance to ED. He received a single dose of intravenous vitamin $\mathrm{K}$ immediately after the unmeasurable PT result was obtained in sample 2 . The third sample for coagulation testing was taken five hours after vitamin $\mathrm{K}$ administration. The result for PT was $<7 \%$ again and result for aPTT was within normal range (Table 1, sample 3).

Since citrate plasma samples showed an unusual opalescence, both samples (sample 2 and sample 
TABLE 1. Coagulation test results obtained at different time points in a patient with detected M-protein lgG- $\lambda$ type.

\begin{tabular}{|c|c|c|c|c|c|c|c|}
\hline & Sample 1 & Sample 2 & Sample 3 & Sample $3^{*}$ & Sample 4 & Sample 5 & $\begin{array}{c}\text { Reference } \\
\text { range }\end{array}$ \\
\hline $\begin{array}{l}\text { Sampling date and } \\
\text { time }\end{array}$ & $\begin{array}{l}\text { June } 2^{\text {nd }} \\
\text { at } 15 \text { pm }\end{array}$ & $\begin{array}{l}\text { June } 2^{\text {nd }} \\
\text { at } 16 \mathrm{pm}\end{array}$ & $\begin{array}{c}\text { June } 2^{\text {nd }} \text { at } 23 \mathrm{pm} \\
\text { after intravenous } \\
\text { vitamin } \mathrm{K} \\
\text { administration }\end{array}$ & $\begin{array}{l}\text { June } 2^{\text {nd }} \text { at } \\
23 \mathrm{pm} \text { and } \\
\text { stored at } 4^{\circ} \mathrm{C} \\
\text { overnight }\end{array}$ & $\begin{array}{c}\text { June } 3^{\text {rd }} \text { at } \\
06: 30 \text { am }\end{array}$ & $\begin{array}{c}\text { June } 3^{\text {rd }} \text { at } 06: 30 \\
\text { am and incubated } \\
\text { at } 37^{\circ} \mathrm{C} \text { for } 30 \\
\text { minutes }\end{array}$ & \\
\hline $\begin{array}{l}\text { Prothrombin time (PT) } \\
\text { (\%) }\end{array}$ & $<7$ & $<7$ & $<7$ & 55 & $<7$ & $<7$ & $\geq 70$ \\
\hline $\begin{array}{l}\text { PT mix test with } \\
\text { normal plasma }(1+1) \\
(\%)\end{array}$ & NP & NP & NP & NP & 67 & NP & NA \\
\hline APTT (s, ratio) & $24(0.8)$ & $25(0.90)$ & $27(1.0)$ & $25(0.90)$ & $29(1.0)$ & $25(0.9)$ & $\begin{array}{c}23-32 \\
(0.8-1.2)\end{array}$ \\
\hline Fibrinogen (g/L) & NP & $<0.8$ & NP & 3.1 & $<0.8$ & $<0.8$ & $1.8-3.5$ \\
\hline TT (s) & NP & 107 & NP & 56.3 & 97.4 & 112 & $14-21$ \\
\hline FII (\%) & NP & $\mathrm{NP}$ & $\mathrm{NP}$ & 139 & 118 & $\mathrm{NP}$ & $70-120$ \\
\hline FV (\%) & NP & $\mathrm{NP}$ & $\mathrm{NP}$ & 154 & 129 & NP & $70-140$ \\
\hline FVII (\%) & NP & NP & NP & 148 & 151 & NP & $70-120$ \\
\hline FX (\%) & NP & NP & NP & 185 & 210 & NP & $70-120$ \\
\hline
\end{tabular}

Sample $3^{*}$ represents sample 3 which was refrigerated until next morning when PT, aPTT, fibrinogen, TT and FII, FV, FVII and FX activities were performed in plasma layer separated from visible precipitate. The results obtained in sample $3^{*}$ were not reported to the clinician due to unmet pre-analytical requirements for coagulation testing.

APTT - activated partial thromboplastin time, TT - thrombin time, NP - not performed, NA - not applicable.

3) were refrigerated (at $4{ }^{\circ} \mathrm{C}$ ) overnight. The next morning these refrigerated plasma samples were visually inspected and precipitate with gelatinous appearance between the cell and plasma layers was visible. Plasma layer above precipitate was separated from sample 3 and the global coagulation tests (PT, aPTT, TT and fibrinogen) were determined (Table 1, sample $3^{*}$ ). In this sample the results of PT and fibrinogen were $55 \%$ and $3.1 \mathrm{~g} / \mathrm{L}$, respectively. Additional measurements of coagulation factor II, V, VII and X activities in this sample were also performed. The results for factor activities showed normal or increased values (Table 1, sample $3^{*}$ ). During night the patient was kept under observation and the next morning a new sample for global coagulation tests was sent to the laboratory. The results for PT and fibrinogen were unmeasurable again, while aPTT result was within reference range and TT was prolonged (97.4 s), as shown in Table 1, sample 4.
PT mixing test showed a correction of PT result to $67 \%$. In order to investigate the cause of unmeasurable PT result, coagulation factor activities were also determined in sample 4 and the values were comparable with those obtained in plasma sample after refrigeration (sample $3^{*}$ ). One plasma portion of sample 4 was also incubated for $30 \mathrm{~min}$ utes at $37{ }^{\circ} \mathrm{C}$ and the results of global coagulation tests were as follows: unmeasurable PT and fibrinogen, prolonged TT and aPTT within reference range (Table 1, sample 4).

The visual inspection of plasma sample after overnight refrigerating as well as the results of coagulation testing described above suggested the possible presence of plasma precipitate of cryoglobulin type. Therefore, further laboratory diagnostics was focused on serum protein electrophoresis and immunofixation of serum and heparin plasma leftovers (Figure 1). The serum sample was incubated $30 \mathrm{~min}$ at $37^{\circ} \mathrm{C}$ prior processing into Capyllaris and 


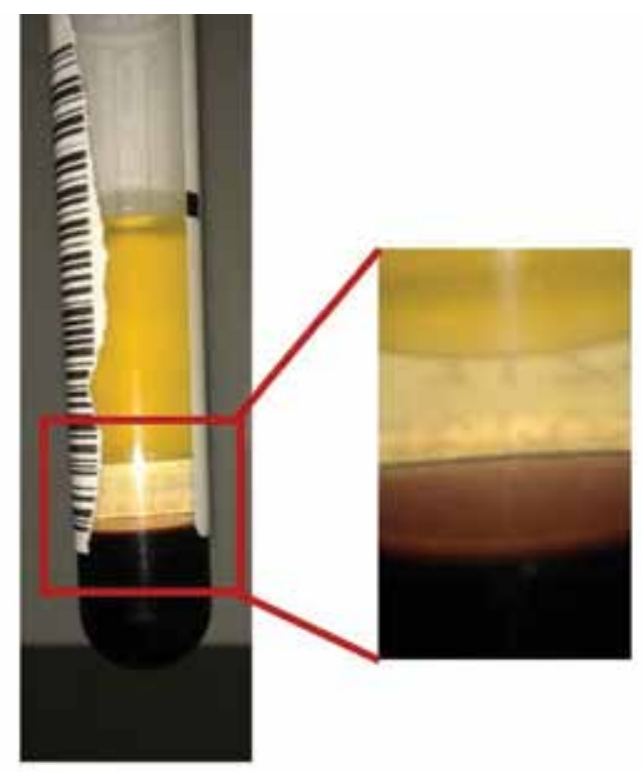

Figure 1. Serum tube centrifuged within one hour from blood sampling showed visible gelatinous precipitate after overnight refrigeration. agarose gel. The plasma and sera samples were processed on Architect $\mathrm{c} 8000$ as stat samples. Analyser signalized inability for measurement due to high viscosity of sample, so serum and plasma were diluted ( $4 x$ for total protein and $10 x$ for $\beta 2-$ microglobulin) with preheated saline prior processing. Total serum protein concentration was $123.0 \mathrm{~g} / \mathrm{L}$ (reference range $66-80 \mathrm{~g} / \mathrm{L}$ ) and serum protein electrophoresis showed a monoclonal peak at a concentration of $47.1 \mathrm{~g} / \mathrm{L}$. Plasma $\beta 2$ microglobulin concentration was $17.36 \mathrm{mg} / \mathrm{L}$ (reference range 0 - $2 \mathrm{mg} / \mathrm{L}$ ). Immunofixation identified monoclonal lgG - lambda (M-lgG- $\lambda$ ) (Figure 2).

\section{Discussion}

We have described a case report of abnormal coagulation test results, i.e. unmeasurable PT and fibrinogen level with significantly prolonged TT and aPTT within reference range in an 88-year old man who presented to ED. These abnormal coagulation test results in a patient not taking any anticoagulant therapy as well as visual inspection of plasma

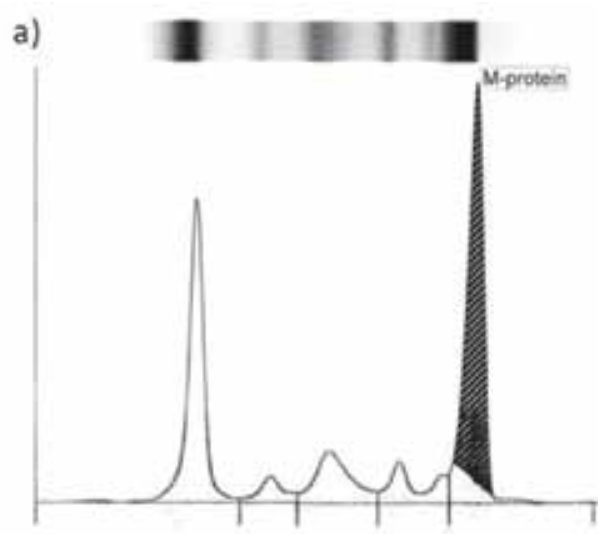

\begin{tabular}{|c|c|c|c|c|}
\hline \multirow[t]{2}{*}{ Nevionsers } & \multicolumn{2}{|c|}{123 91 (66- 81) } & \multicolumn{2}{|c|}{ ANG: $0,46 \quad(0,80-2,00)$} \\
\hline & $\%$ & Ret int \% & gll & Ret. int $g$ h. \\
\hline Albumin & 31,4 & $55,8-66,1$ & 38,6 & $40.2-47,6$ \\
\hline Alpha 1 & 4,0 & $2,9-4,9$ & 4,9 & $2,1-3,5$ \\
\hline Alpha 2 & 11,6 & $7,1-11,8$ & 14,3 & $5,1-8,5$ \\
\hline Beta & 8,1 & $8,4+13,1$ & 10,0 & $6,0 \cdot 9,4$ \\
\hline Gamma & 44,9 & $11,1 \cdot 18,8$ & 55,2 & $8,0 \cdot 13,5$ \\
\hline M-protein & 38,3 & & 47,1 & \\
\hline
\end{tabular}

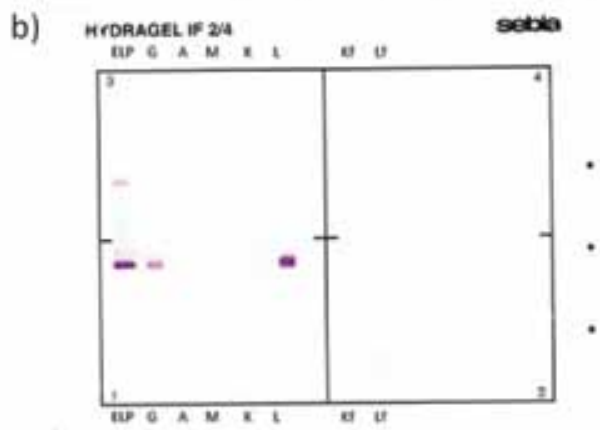

FiguRE 2. Serum electrophoresis detected M-protein in gamma fraction (a) and immunofixation identified monoclonal immunoglobulin G lambda (b). 
sample after overnight refrigerating have suggested the presence of M-protein in circulation. Further laboratory diagnostics confirmed the presence of M-protein IgG- $\lambda$ and possible diagnosis of monoclonal gammopathy. Unfortunately, since the patient refused hospitalization after medical examination in the ED, it was not possible to set a definitive diagnosis. However, on the basis of specific additional laboratory diagnostic work-up, a monoclonal gammopathy as an underlying pathophysiological condition can be argued in our patient.

Clinical manifestations of monoclonal gammopathies are heterogeneous and include monoclonal immunoglobulin production, decreased immunoglobulin secretion by normal plasma cells, impaired haematopoiesis with anaemia, defect in haemostasis, osteolytic bone lesions, hypercalcaemia and renal dysfunction (7).

Haemostatic disorders include both, thrombotic and haemorrhagic disorders (8-10). The monoclonal protein itself may have intrinsic prothrombotic properties $(8,11)$. Haemorrhagic disorders in patients with monoclonal gammopathies can be result of various mechanisms, including factor deficiencies due to amyloid adsorption, M-proteins with inhibitory activity to coagulation factors, impaired fibrin monomer polymerization or systemic fibrinolysis (12). The extent of bleeding correlates with the M-protein concentration in plasma, suggesting that the M-protein may be important in the pathophysiology of the haemorrhagic diathesis. Abnormal screening coagulation test results, such as PT, aPTT and TT are common in patients with plasma cell neoplasms (13). However, pathological results for coagulation tests are not always associated with clinically significant bleeding. The nature and the extent of impact and interference on coagulation test results are different in individual patients with monoclonal gammopathies (6).

In the patient described in this study PT was unmeasurable, but activities of coagulation factors II, $\mathrm{V}, \mathrm{VII}$ and $\mathrm{X}$ in the same sample showed normal or even increased values. These results suggest that unmeasurable PT result was not due to decreased factor activities. Correction of PT result to $67 \%$ in mixing test further excluded an inhibitory effect of M-protein on coagulation factors. Further, TT result was prolonged in all plasma samples. The common causes for TT prolongation are: decreased fibrinogen concentration, dysfibrinogenemia, increased fibrin/fibrinogen degradation products and heparin or other circulating anticoagulants (14). Since the patient had a normal fibrinogen level, as shown in plasma sample after separating precipitate layer, hypofibrinogenemia could not be considered as the cause of TT prolongation in this case. On the other hand, it is known that $\mathrm{M}$ protein can inhibit fibrin polymerization resulting in prolonged TT and abnormal clot formation (15). It has been shown that prolonged TT was commonly encountered abnormal clotting time test result in patients with monoclonal gammopathies $(6,13,16)$. In the Pandey's study prolongation of TT correlated with serum immunoglobulin concentrations. Despite the relatively frequent abnormal TT result, clinical bleeding manifestations were observed only in a minority of patients who possibly have other associated haemostatic defects. It is known that abnormally high concentrations of $\mathrm{M}$ protein and associated increased blood viscosity can also impair fibrin polymerization $(17,18)$. Therefore, we suspect that the coagulation abnormality that could be the most closely associated with nose-bleeding symptom in our patient was the prolongation of TT rather than PT. High concentration of lgG M-protein detected in our patient could be responsible for inhibition of fibrin polymerization thus accounting for the patients' clinical symptom of fresh blood occurrence during nose blowing.

According to the present literature data, it is obvious that monoclonal gammopathies produce a heterogeneous pattern of impacts and interferences on individual coagulation test results and that abnormal result of global coagulation test does not necessarily indicate pathological result. The results of different studies indicate that monoclonal immunoglobulins may target any of haemostatic components. Therefore, further evaluation for individual patient should be guided according to the coagulation abnormalities identified in the laboratory. It can be assumed that 
thromboelastometry as a method of whole blood coagulation testing could be potentially helpful in eliciting normal in vivo coagulation in our patient with unmeasurable PT result. However, this method was not available in our laboratory.

The main limitation of this case study was that we were not able to monitor patient during his treatment since he refused hospitalization. Because of limited quantity of sample, we were not able to perform further laboratory diagnostics, like measurement of free light chains. Furthermore, when cryglobulin was suspected, there was no possibility for repeated sampling and transport at $37^{\circ} \mathrm{C}$ or for the investigation for rheumatoid factor as a potential cause of interference on the coagulation test results.

It should be emphasized that none of the results obtained in the sample 4 was reported to the clinician since it did not meet pre-analytical requirements for coagulation testing. However, the visual inspection as well as coagulation testing of this sample had a considerable impact on the clarification of our patient case in both, directing the further laboratory diagnostics, as well as understanding the nature of impact and interference of $\mathrm{M}$ protein on individual coagulation tests.

\section{References}

1. Lippi G, Pasalic L, Favaloro EJ. Detection of mild inherited disorders of blood coagulation: current options and personal recommendations. Expert Rev Hematol 2015;8:527-42. http://dx.doi.org/10.1586/17474086.2015.1039978.

2. Zareh $M$, Davis $A$, Henderson S. Reversal of warfarin-induced hemorrhage in the emergency department. West J Emerg Med 2011;12:386-92. http://dx.doi.org/10.5811/westjem.2011.3.2051.

3. King Rl, Florkowski CM. How paraproteins can affect laboratory assays; spurious results and biological effects. Pathology 2010;42:397-401. http://dx.doi.org/10.3109/00313025. 2010.493868.

4. Dimeski G. Interference testing. Clin Biochem Rev 2008; 29:S43-8.

5. Nanda SK, Sarangi R, Ray L, Kumar A, Padhi S. Factitious Biochemical Reports which are Caused Due to Paraproteinaemia in Multiple Myeloma - A Case Report. J Clin Diag Res 2013;7:350-2. http://dx.doi.org/10.7860/jcdr/ 2013/5173.2765.
In conclusion, our case study revealed interference of M-protein on coagulation test results. The results are misleading to the clinician and the patient is exposed to risk of unfavourable outcome in case of inappropriate therapeutic intervention, such as vitamin $\mathrm{K}$ administration in our patient.

A message arising from this case study is that laboratory evaluation of potential presence of M-protein in circulation should be considered as the next diagnostic step in a patient not taking any anticoagulant therapy but with unexplained and unexpected coagulation test results. At first, repeated blood sampling at $37^{\circ} \mathrm{C}$ should be considered. The next step should be refrigeration of the plasma sample overnight at $4{ }^{\circ} \mathrm{C}$ in order to inspect for the potential presence of M-protein that precipitate at cold temperatures. In case of any suspicion of the presence of paraproteins in circulation, further diagnostic approach should include measurements of total protein concentration, immunoglobulins $G, A$ and $M$, protein electrophoresis and immunofixation and $\beta 2$-microglobulin, if possible.

\section{Potential conflict of interest}

None declared.

6. Huang $H, L i H, L i D$. Effect of serum monoclonal protein concentration on haemostasis in patients with multiple myeloma. Blood Coagul Fibrinolysis 2015;26:555-9. http://dx.doi. org/10.1097/MBC.0000000000000296.

7. Hasnain Q, Adil S, Asghar S. Multiple myeloma presenting with bleeding diathesis. Biomedica 2007;23:144-5.

8. Takamiya O, Machida S, Okuda M, Nojima J, Koreeda C, Kubara K. A non-immunological phospholipid-dependent coagulation inhibitor associated with IgG $\mathrm{g}$-type multiple myeloma. Am J Hematol 2004;75:34-9. http://dx.doi. org/10.1002/ajh.10449.

9. Eby CS. Bleeding and thrombosis risks in plasma cell dyscrasias. Hematology Am Soc Hematol Educ Program 2007:15864. http://dx.doi.org/10.1182/asheducation-2007.1.158.

10. Coppola A, Tufano A, Di Capua M, Franchini M. Bleeding and thrombosis in multiple myeloma and related plasma cell disorders. Semin Thromb Hemost 2011;37:929-45. http://dx.doi.org/10.1055/s-0031-1297372. 
11. Bellotti V, Gambo G, Merlini G, Montani N, BucciareIli $E$, Stoppini $M$, et al. Study of three patients with monoclonal gammopathies and 'lupus-like' anticoagulants. $\mathrm{Br} J$ Haematol 1989;73:221-7. http://dx.doi. org/10.1111/j.1365-2141.1989.tb00256.x

12. Liebman HA. Hemostatic defects associated with dysproteinemias. In: R. Hoffman et al, eds. Hematology: basic principles and practice, 3rd ed. New York: Churchill Livingstone 2000. p. 1996-9.

13. Pandey S, Post SR, Alapat DV, Smock KJ, Post GR. Prolonged prothrombin time correlates with serum monoclonal protein concentration in patients with plasma cell dyscrasia. Int J Lab Hematol 2013;35:421-7. http://dx.doi.org/10.1111/ ijlh.12036.

14. Colwell NS, Tollefsen DM, Blinder MA. Identification of a monoclonal thrombin inhibitor associated with multiple myeloma and a severe bleeding disorder. $\mathrm{Br} J \mathrm{Haema-}$ tol 1997;97:219-26. http://dx.doi.org/10.1046/j. 13652141.1997.d01-2145.x.
15. Gabriel DA, Smith LA, Folds JD, Davis L, Cancelosi SE. The influence of immunoglobulin ( $\mathrm{gG}$ ) on the assembly of fibrin gels. J Lab Clin Med 1983;101:545-52.

16. Robert F, Mignucci M, McCurcy SA, Maldonado $N$, Lee JY. Hemostatic abnormalities associated with monoclonal gammopathies. Am J Med Sci 1993;306:359-66. http:// dx.doi.org/10.1097/00000441-199312000-00001.

17. Zangari M, Elice F, Fink L, Tricot G. Hemostatic dysfunction in paraproteinemias and amyloidosis. Semin Thromb Hemost 2007;33:339-49. http://dx.doi.org/10.1055/s-2007-976169.

18. O'Kane MJ, Wisdom GB, Desai ZR, Archbold GP. Inhibition of fibrin monomer polymerisation by myeloma immunoglobulin. J Clin Pathol 1994;47:266-8. http://dx.doi. org/10.1136/jcp.47.3.266. 